$66 \frac{3263}{\mathrm{DP}-1266}$

\title{
REMOTE DECONTAMINATION OF EQUIPMENT IN A RADIOCHEMICAL SEPARATIONS PLANT
}

\author{
A. J. HILL
}

SRL $O R D$ COPY

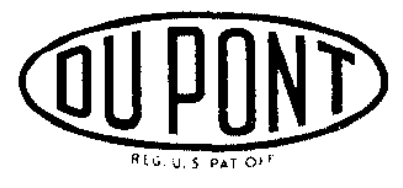

Savannah River Laboratory

Aiken, South Carolina 


\section{NOTICE}

This report was prepared as an account of work sponsored by the United States Government. Neither the United States nor the United States Atomic Energy Commission, nor any of their employees, nor any of their contractors, subcontractors, or their employees, makes any warranty, express or implied, or assumes any legal liability or responsibility for the accuracy, completeness or usefulness of any information, apparatus, product or process disclosed, or represents that its use would not inf ringe privately owned rights.

Printed in the United States of America

Available from

National Technical Information Service

U. S. Department of Commerce

5285 Port Royal Road

Springfield, Virginia 22151

Price: Printed Copy $\$ 3.00$; Microfiche $\$ 0.95$ 


\title{
663263
}

DP- 1266

Engineering and Equipment

(TID-4500, UC-38)

\section{REMOTE DECONTAMINATION OF EQUIPMENT IN A RADIOCHEMICAL SEPARATIONS PLANT}

\author{
by \\ A. J. $\mathrm{Hill}$ \\ Major Contributors \\ A. S. Barab \\ R. H. Hobert
}

Approved by

A. S. Jennings, Research Manager

Separations Engineering Division

September 1971

E. I. DU PONT DE NEMOURS \& COMPANY

SAVANNAH RIVER LABORATORY

AIKEN, S. C. 29801

CONTRACT AT(07.2)・1 WITH THE

UNITED STATES ATOMIC ENERGY COMMISSION 


\begin{abstract}
At the Savannah River Plant, process equipment from the radiochemical separations plants is decontaminated rapidly and economically by scouring with high-velocity jets of water and by applying dilute solutions of simple reagents at elevated temperatures. The decontamination, disassembly, and some maintenance and auxiliary work are done by remote operation to minimize exposure of personnel to radiation. In over five years of operation, this technique has made possible the salvage and repair of much valuable equipment and has significantly reduced radiation exposure during maintenance work.
\end{abstract}




\section{CONTENTS}

Page

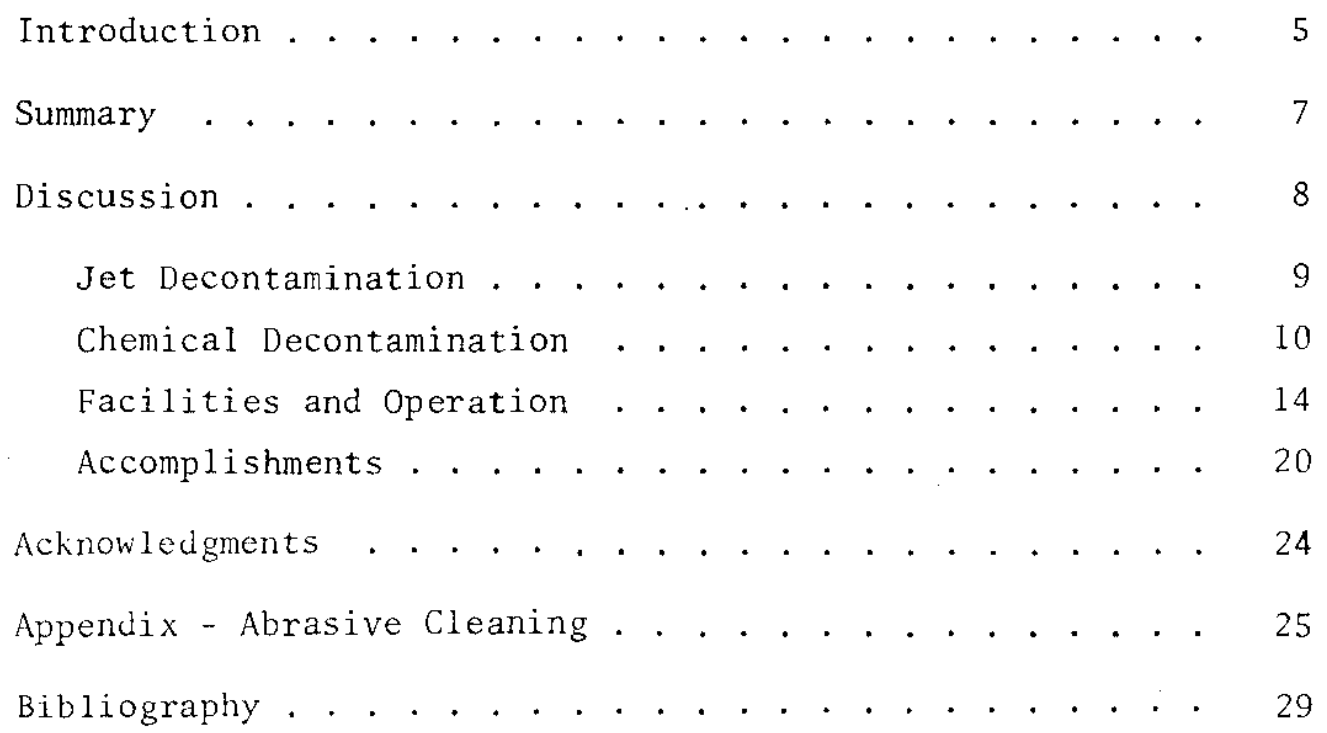




\section{LIST OF TABLES AND FIGURES}

Table

Page

I Typical savings on Equipment . . . . . . . . . 22

Figure

1 Removal of Fission Products from Contaminated

Type 304 Stainless Steel. . . . . . . . . . . . 12

2 Decontamination Facility (Plan View) . . . . . . 15

3 Decontamination Facility (Perspective View) . . 16

4 Operating Area of Decontamination Facility . . . 17

5 High-Pressure Pump for Decontaminating Equipment . 17

6 Electromechanical Manipulator . . . . . . . . 19

7 Decontaminating the Top of a Centrifuge . . . . 21 


\section{INTRODUCTION}

In the radiochemical separations facilities for recovering uranium and plutonium at the Savannah River Plant, equipment that is removed from service is usually contaminated with highly radioactive fission products that are not readily removed. Contaminated equipment that is to be repaired or modified, or even equipment to be discarded, must be decontaminated sufficiently to avoid exposing personnel to radiation or contaminating the environment.

A study of the literature and consultation with other atomic energy installations indicated it should be possible to decontaminate large stainless steel process vessels sufficiently for direct maintenance. However, because of the uncertain and occasionally very poor results obtained with existing techniques, an experimental program was undertaken to develop effective and reliable methods for decontaminating process equipment. The reductions in radiation levels required were as much as 1000-fold. Both chemical and physical methods were investigated; the former using chemical reagents in aqueous solution, and the latter using both wet and dry abrasive techniques and high-velocity water jets. 
$-6-$ 


\section{SUMMARY}

Industrial cleaning techniques were adapted to the remote decontamination of process equipment in the separations areas of the Savannah River Plant. Of the methods examined, the most adaptable and economical were scouring with jets of hot water $(150-250 \mathrm{ft} / \mathrm{sec})$, or with jets of cold water at higher velocity $(400-700 \mathrm{ft} / \mathrm{sec})$, and by applying hot $\left(80-90^{\circ} \mathrm{C}\right)$, dilute solutions of simple chemicals. Abrasive techniques, although effective, cause waste disposal problems if used for cleaning highly contaminated equipment.

After various decontamination techniques in laboratory and semiworks tests were evaluated, an experimental facility was installed in the plant to test jet cleaning on actual plant equipment. The combination of chemical treatments and jet cleaning was very successful; it became possible to decontaminate and repair process equipment for reuse and even recover discarded equipment that had been impossible to decontaminate previously because of excessive radiation levels. In the first six months of operation, the savings exceeded the cost of the experimental facility.

The experimental installation was eventually adopted for routine production use as a decontamination, inspection, and minor repair facility. Some of the original equipment was replaced, improvements were made, and a second similar installation was constructed in the companion separations plant. Savings are estimated to be at least $\$ 500,000$ per year for each of the two plants based on more than five years of operating experience. 


\section{DISCUSSION}

Before the methods described for remote decontamination were developed, some moderately contaminated equipment was decontaminated manually by scrubbing with cleaning agents and abrasives or by soaking with chemicals at ambient temperature. Large, heavily contaminated equipment, such as process evaporators, condensers, and centrifuges, were usually buried instead of repaired because their high radiation levels precluded cleaning.

As the versatility and capacity of the separations plants increased, rapid and effective decontamination methods were needed because process equipment required replacement or interchange without costly delays. The requirements for the necessary decontamination facility were: 1) remote methods that would minimize exposure to personnel, 2) techniques that were chemically compatible with materials handled in the separations process and that would not damage equipment, and 3) equipment that could be incorporated within existing facilities, if possible.

A study of decontamination of chemical separations plants was conducted in 1960 comprising a literature search (see Bibliography) and discussions with knowledgeable persons in the field. The survey did not disclose a preferred technique or universal decontaminant because the reported procedures were developed for specific facilities and processes. Therefore, an experimental program was initiated to develop improved methods for decontaminating process equipment at the Savannah River Plant.

At the inception of the experimental program, two stages of decontamination were considered necessary. The first stage was to be a gross decontamination of equipment, either in its operating position or in a nearby shielded cell. This decontamination step was expected to reduce the radiation and contamination so that the equipment could be removed safely from the shielded zone without high rates of exposure to personnel and without significant potential for contamination of the surroundings. It was expected that extensive secondary decontamination would still be required before direct maintenance, and that the second-stage decontamination could be done more effectively in another location. The construction of a separate facility or extensive modification of some existing shielded enclosure was considered necessary; either would have required a significant capital investment. Cost estimates for separate facilities ranged from 2.5 to 8 million dollars. However, as a result of the jet and chemical cleaning techniques developed in the experimental program, the objectives were met by 
minor modification of the existing facilities. The modifications included a biological shielding wall, a heavy duty electromechanical manipulator, and a high pressure pump at a total cost of $\$ 125,000$.

The development of both the jet and chemical cleaning techniques and the test facilities are described in the following paragraphs.

\section{JET DECONTAMINATION}

Jet cleaning in industry includes both low-velocity streams from water hoses (30-50 ft/sec) and high-velocity jets (200-700 $\mathrm{ft} / \mathrm{sec}$ ) from high pressure liquid pumping systems, as well as various steam- and air-pressured devices. Water at the normal pressures used in hoses (50-100 psig) does not usually provide the velocity and impact required to remove radioactive contamination. Dry steam has also been found ineffective. By contrast, water at much higher velocities $(200-700 \mathrm{ft} / \mathrm{sec})$ or saturated steam with an entrained cleaning agent are effective.

Jet cleaning is more effective than soaking. For immersion of large pieces of equipment, a very large vat filled with cleaning solutions is required. In addition, an equivalent capacity in shielded tankage is required for retention of solutions pending reuse or disposal. Much smaller volumes of solutions can be used in jet cleaning, and the solutions need not be reused. With jet cleaning, nozzles that rotate about two axes can be used to clean the interior of tanks, so that it is not necessary to fill a tank in order to contact all surfaces. Furthermore, continuous pumping of the decontaminating solutions against the surface to be decontaminated permits rinsing and minimizes redeposition of activity.

To obtain the scouring action that is required for decontamination with high-velocity jets, the nozzle shape is very important. Those found most effective are: 1) tapered nozzles with a circular orifice producing a solid stream, and 2) nozzles with narrow slots producing thin fans with an angle of about $15^{\circ}$. Nozzles designed for highpressure jetting are hardened and ground to a smooth finish to minimize dispersion of the exit stream.

High-velocity jet cleaning cannot be used to decontaminate all equipment. Some equipment with complex internal shapes still requires an internal rinse or flush. For example, to decontaminate the interior surfaces of centrifuges, condenser tubes, and pump casings, it is still necessary to fill them with chemical cleaning agents or to circulate solutions through them. In this event, however, the volumes of cleaning reagents required are usually much smaller than the amounts required to submerge or fill large process vessels. Abrasive cleaning combined with jet cleaning was investigated in semiworks tests, but because of potential equipment damage and the 
eventual effectiveness of water jet cleaning the abrasive work was discontinued. Abrasive cleaning techniques, including the results of semiworks tests, are described in the Appendix.

\section{CHEMICAL DECONTAMINATION}

Chemical decontaminating reagents are usually used on surfaces that cannot be reached effectively by high-velocity water streams, or occasionally when a further reduction in activity level is required after jet cleaning. Reagents can be applied in appropriate concentrations and small volumes by means of a conventional steam hydrocleaner for hot solutions or by small chemical pumps for cold solutions. Thus, detergents and chemical reagents can be made up or supplied in concentrated form in small drums to provide flexibility with economy of space; in special instances where mixed solutions are required, a simple portable mixer is adequate. Large solution makeup tanks with agitators and heating coils have not been required. There is no advantage in applying reagents at high velocity because the contact time is too short for effective chemical reactions; application at high velocity only leads to use of a larger volume of solution. High-velocity water jets are used for their scouring action both before and after the application of chemical reagents.

For a number of years it had been known that a two-step process was required for the most effective chemical decontamination of stainless steel equipment. The conditioning effect of alkaline permanganate solution as the first reagent was well known, particularly for decontaminating nuclear reactors and reactor components. In these treatments the second step was either citric, oxalic, or strong nitric acid. The most effective second reagent was a mixture of hydrofluoric acid in nitric acid, used commercially for pickling stainless steel. However, the latter, designated 3-20 reagent ( $3 \%$ hydrofluoric acid - $20 \%$ nitric), attacks stainless steel rapidly, particularly at the welds, and is a poor choice for decontaminating equipment that must be immersed in such solution for several hours. The typical first step reagent, a solution of alkaline permanganate, ( $3 \%$ potassium permanganate in $16-18 \%$ sodium hydroxide) was not particularly effective alone as a decontaminant.

In the laboratory, selected cleaning reagents for removing fission products from Type 304 stainless steel were evaluated with planchets contaminated with acidic high-activity waste solution. It was found that a two-step process similar to that described above but using dizute reagents at elevated temperature was effective in decontaminating stainless steel with little corrosion. The laboratory tests were confirmed on equipment decontaminated in the plant. The preferred process was treatment with a dilute solution of alkaline permanganate followed by a dilute nitric acid-potassium 
fluoride mixture. For the first step, a solution of about $0.1 \mathrm{M}$ $\mathrm{KMnO}_{4}$ in $1.3 \mathrm{M} \mathrm{NaOH}$ represented approximately the minimum concentration for consistently good results. For the second step, the most effective simple reagent was a solution of $0.1 \mathrm{M} \mathrm{KF}$ in $0.5 \mathrm{M}$ $\mathrm{HNO}_{3}$. The latter solution was also the most effective single decontaminant but was much more effective in the two-step process. The addition of a small amount of aluminum nitrate to reduce corrosion did not reduce the effectiveness of the two-step system. However, the fluoride attack on stainless steel is sufficiently low that this added protection generally is not needed. Dilute oxalic acid and hydroxylamine sulfate have also been found effective in certain applications for the second step. The results of the tests are summarized in Figure 1, illustrating both the beta and gamma decontamination which can be obtained with selected decontaminating reagents applied in two stages with a water rinse between each stage.

The temperature of application should be at least $85^{\circ} \mathrm{C}$ for optimum results in decontamination with dilute solutions. If the temperature is $85^{\circ} \mathrm{C}$ or above, treatment beyond 5-10 minutes usually is not necessary (Figure 1 ). If additional decontamination is desired, the two-step process should be repeated rather than extending the time of treatment. A water rinse between the alkaline and acidic solutions is necessary both for effective decontamination and for avoiding acid-base reactions.

Decreasing the concentration of either sodium hydroxide or nitric acid below the recommended minimum levels decreases the effectiveness of the decontaminant. Experience has also shown that there is little or no advantage in increasing the concentration of either reagent; strong nitric acid has the adverse effect of decreasing the solubility of fluoride complexes. Increasing the fluoride concentration of the second step improves decontamination, but results in increased corrosion of stainless steel. Eliminating potassium permanganate in the first step or potassium fluoride in the second step reduces the effectiveness of the two-step decontamination process; neither sodium hydroxide nor nitric acid alone are particularly good decontaminants for fission products. Results of these tests are shown in Figure 1.

Several proprietary formulations for decontamination were as effective as the recommended dilute reagents, but were costly when applied at recommended strengths; when diluted, they are much less effective. Detergents are beneficial primarily for removing activity from oily surfaces. Several commercial detergents were tested, ranging from a relatively mild household cleaner to strongly alkaline industrial cleaners, including a detergent developed specifically for decontamination. In general, the fission product activity on non-oily stainless steel was reduced about a factor of two by the various detergents at $2 \%$ concentration and $85^{\circ} \mathrm{C}$; higher 


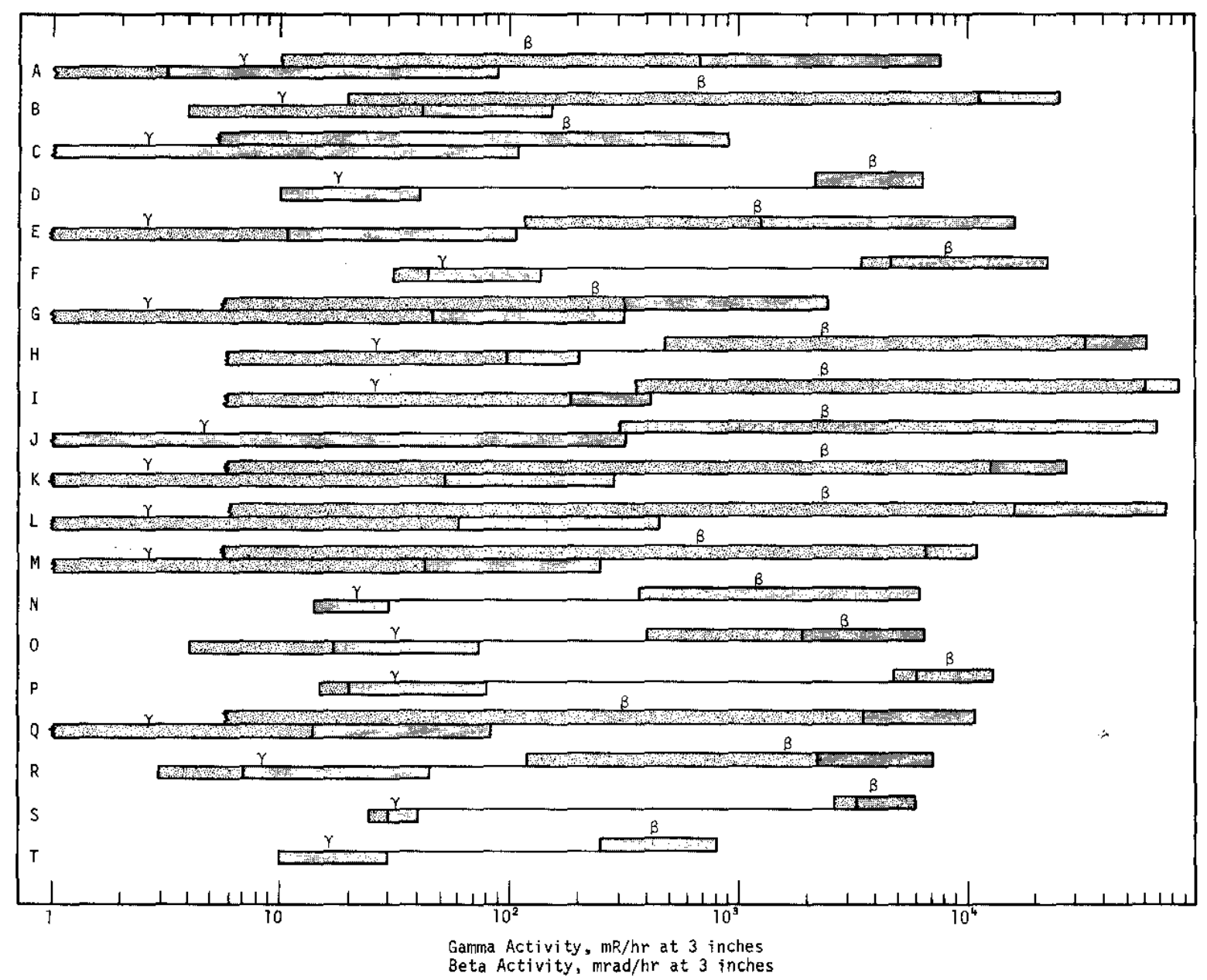

FIG. $?$ REMOVAL OF FISSION PRODUCTS FROM CONTAMINATED TYPE 304 STAINLESS STEEL (A11 solutions used at $85^{\circ} \mathrm{C}, 75$ minutes except where stated otherwise)

Indicates limit of instrument sensitivity, not limit on decontamination

Step 1 Treatment 1 Step 2 Treatment 


\section{Treatments}

A: 1. 1.3M Sodium Hydroxide, 0.13M Potassium Permanganate

2. 0.12M Potassium Oxalate

B: 1. 4M Sodium Hydroxide, 0.13M Potassium Fluoride

2. $0.5 \mathrm{M} \mathrm{Oxalic} \mathrm{Acid}$

C: 1. 0.5M Nitric Acid, 0.1M Potassium Fluoride

D: 1. 0.5M Nitric Acid, 0.05M Potassium Fluoride

E: 1. 0.5M Nitric Acid, 0.1M Potassium Fluoride

2. Repeat Step 1

F: 1. 0.5M Nitric Acid, 0.5M Potassium Fluoride

2. Repeat Step 1

G: 1. 1.3M Sodium Hydroxide, 0.13M Potassium Permanganate

2. $0.5 \mathrm{M}$ Nitric Acid, $0.1 \mathrm{M}$ Potassium Fluoride

$\mathrm{H}: \quad$ 1. 5 minutes at $85^{\circ} \mathrm{C}$

2. 5 minutes at $30^{\circ} \mathrm{C}$

I: 1.5 minutes at $30^{\circ} \mathrm{C}$

2. 5 minutes at $85^{\circ} \mathrm{C}$

J: 1. 1.25M Sodium Hydroxide, 0.13M Potassium Permanganage - 5 minutes

2. $0.2 \mathrm{M}$ Nitric Acid, $0.05 \mathrm{M}$ Aluminum Nitrate, $0.7 \mathrm{M}$ Potassium Fluoride - 5 minutes

K: 1. 1.25M Sodium Hydroxide, 0.13M Potassium Permanganate - 15 minutes

2. $0.2 \mathrm{M} \mathrm{Nitric} \mathrm{Acid,} \mathrm{0.05M} \mathrm{Aluminum} \mathrm{Nitrate,} \mathrm{0.1M} \mathrm{Potassium} \mathrm{Fluoride} \mathrm{-} 5$ minutes

L: 1. 1.25M Sodium Hydroxide, 0.13M Potassium Permanganate - 5 minutes

2. $0.2 \mathrm{M} \mathrm{Nitric} \mathrm{Acid,} \mathrm{0.05M} \mathrm{Aluminum} \mathrm{Nitrate,} 0.1 \mathrm{M}$ Potassium Fluoride - 15 minutes

M: 1. 1.25M Sodium Hydroxide, 0.13M Potassium Permanganate - 15 minutes

2. $0.2 \mathrm{M} \mathrm{Nitric} \mathrm{Acid,} 0.05 \mathrm{M}$ Aluminum Nitrate, $0.7 \mathrm{M}$ Potassium Fluoride - 15 minutes

N: 1. Single Step Treatment

(Average of Detergents at $2 \%$ Concentration)

$0: \quad 1.1 .25 \mathrm{M}$ Sodium Hydroxide

2. $0.5 \mathrm{M}$ Nitric Acid, 0.05M Potassium Hydroxide

P: 1. 0.25M Sodium Hydroxide

2. Repeat Step 1

Q: 1. 4M Sodium Hydroxide, 0.13M Potassium Permanganate

2. $0.5 \mathrm{M}$ Nitric Acid, 0.05M Potassium Fluoride

R: 1. 4M Sodium Hydroxide

2. $0.5 \mathrm{M}$ Nitric Acid

S: 1. 1.6M Nitric Acid

2. Repeat Step 1

T: 1. 0.5M Nitric Acid 
concentrations do not improve the results. In contrast, the recommended dilute reagents decreased activity by a factor of 100 in similar tests.

Promising results were obtained with several proprietary reagents for rust removal and with aluminum cleaners. Such reagents may be of value as substitutes for the two-step process in special applications such as the decontamination of carbon steel framework.

When reagents are used to clean the interiors of vessels, the solutions should be removed continuously from the vessels, or the solutions should be circulated or agitated to reduce the potential for redeposition of radioactivity from the liquid. Agitating solutions in vessels by steam sparging helps keep the solutions hot. Much of the advantage of using hot solutions in decontamination may be lost by redeposition of radioactive material if the solutions are allowed to cool while in contact with the equipment being cleaned.

\section{FACILITIES AND OPERATION}

The decontamination facility (Figure 2) is a cell in a heavily shielded section of a separations building. The cell has a stainless steel liner that forms a tank $13 \mathrm{ft}$ wide, $20 \mathrm{ft}$ long, and $14 \mathrm{ft}$ deep (Figure 3). Above the tank is a catwalk extending along one end and a side. The cell was originally designed to make it possible to work from the catwalk on contaminated equipment submerged in water for gamma shielding. The tank is no longer filled with water. Instead, a steel and lead shielding wall with three lead-glass windows was installed along the front of the catwalk at the end of the cell. An airlock at the corner of the end and side catwalks protects personnel behind the shield from airborne contamination during decontamination operations, but the airlock allows access to the side catwalk when necessary unless the radiation level in the decontamination cell prohibits entry. Thus, from the protected zone behind the wall, operators can decontaminate equipment in the tank and observe the work without exposure to the intense radiation, and without special protective clothing (Figure 4). Normally, overalls or laboratory coats, shoe covers, and cotton work gloves provide adequate contamination protection; respiratory protection is not needed.

A positive displacement pump (Figure 5) with a capacity of 28 gpm at 3000 psig is installed in an adjacent corridor as a source of high pressure water. The pump discharge is piped into the decontamination facility through one of the access ports in the shielding wall, and terminates over the end of the tank. Highpressure jet nozzles within the facility are connected by 

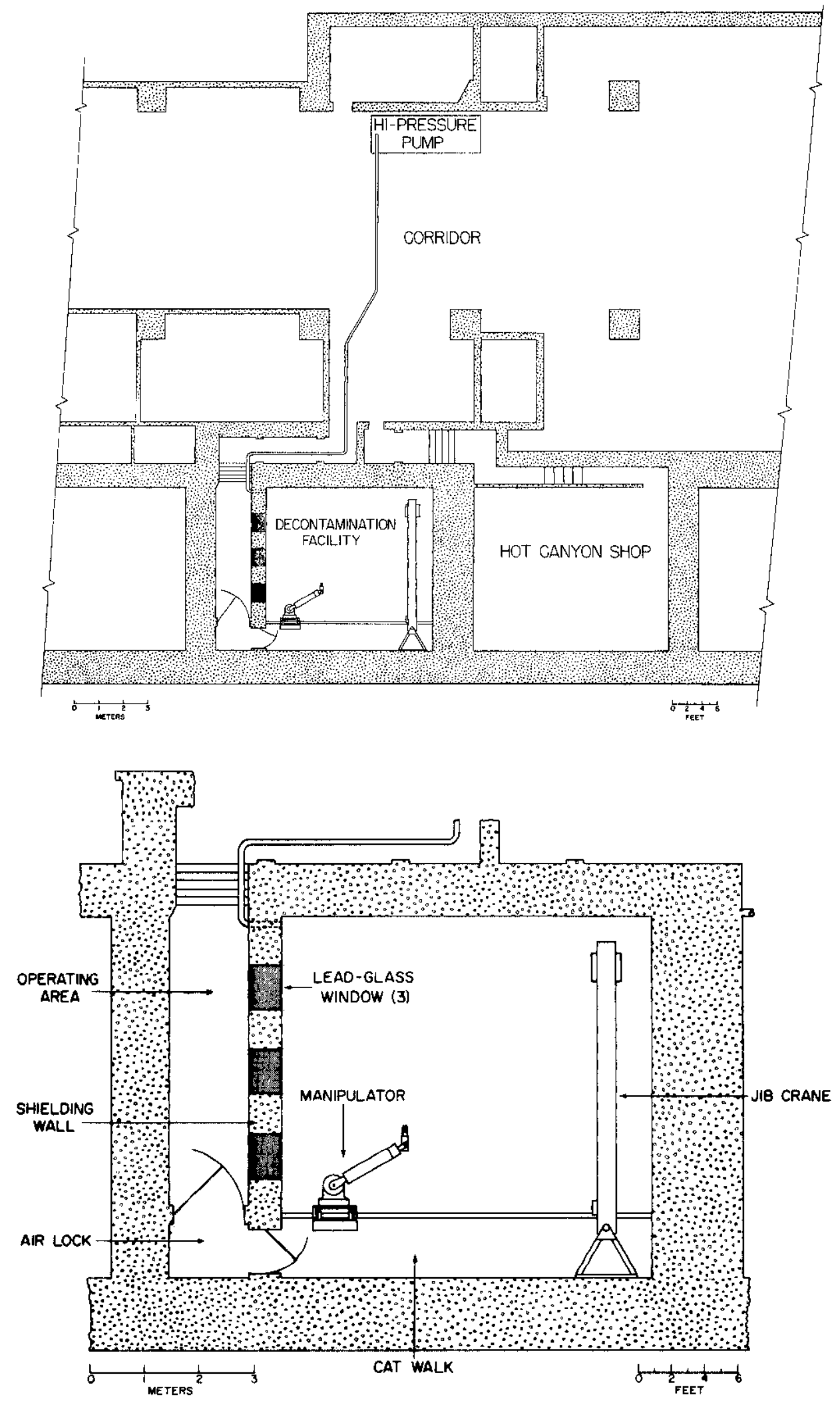

Fig. 2 DECONTAMINATION FACILITY (PLAN VIEW) 


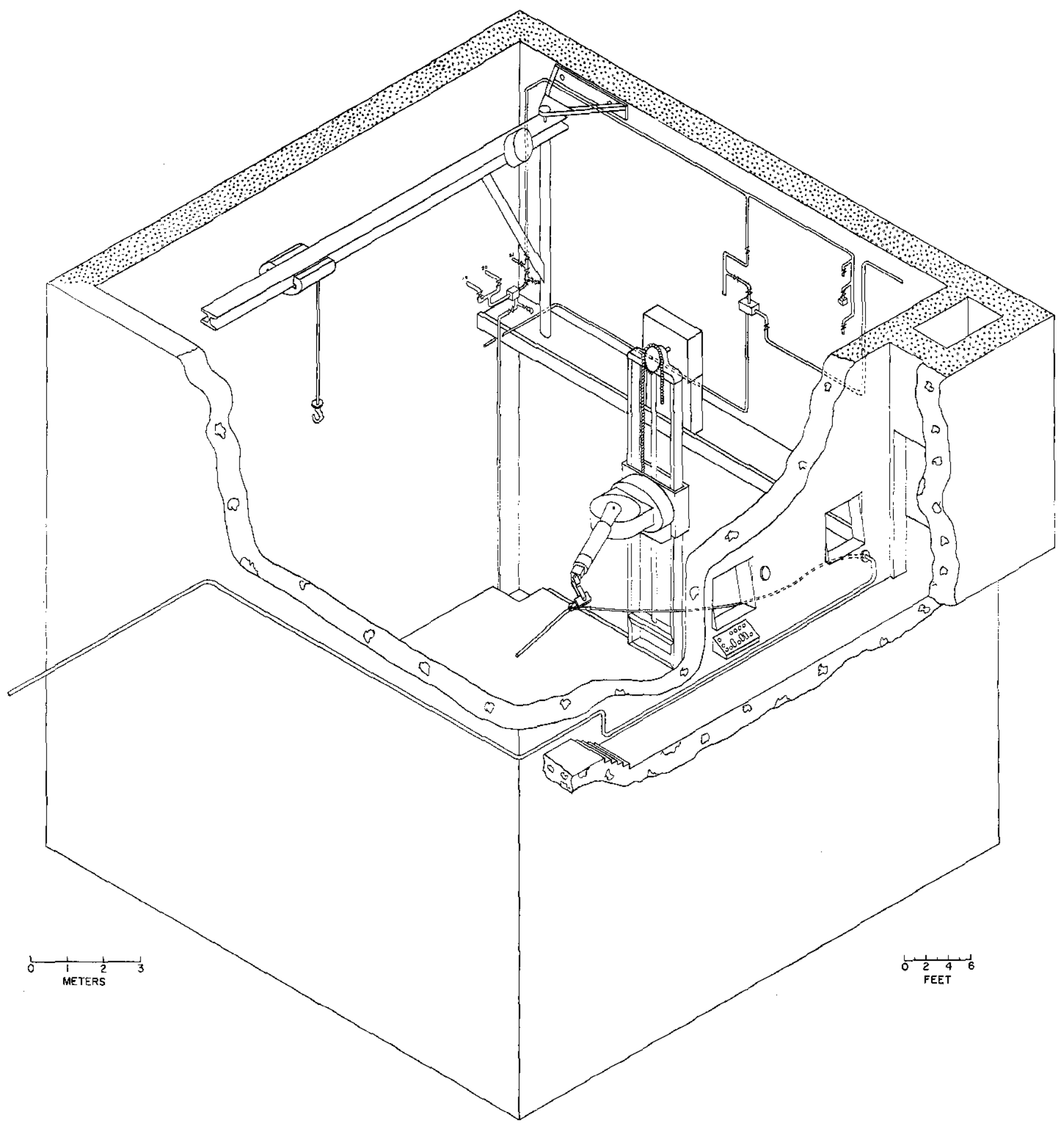

FIG. 3 DECONTAMINATION FACILITY (PERSPECTIVE VIEW) 


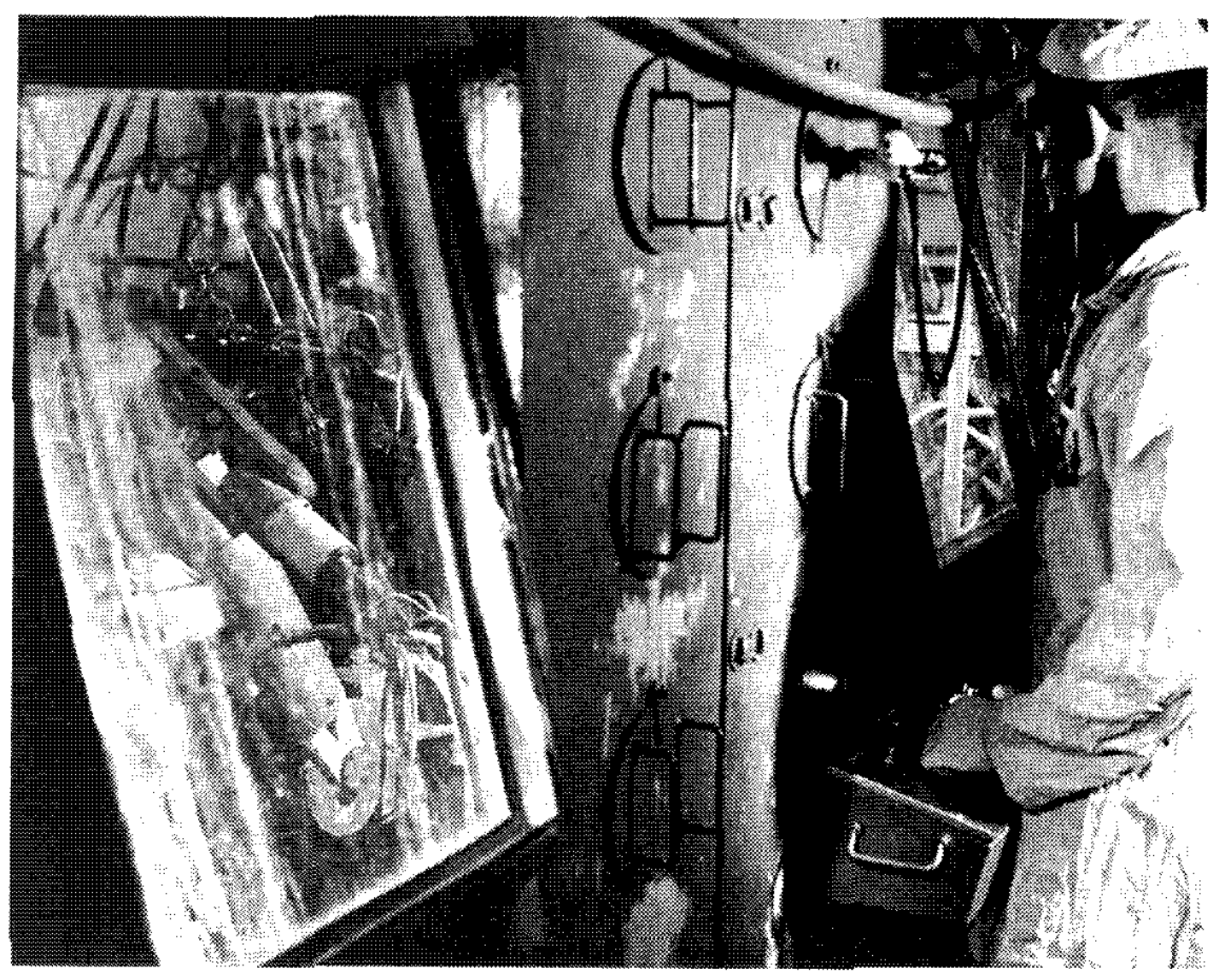

FIG. 4 OPERATING AREA OF OECONTAMINATION FACULTYY

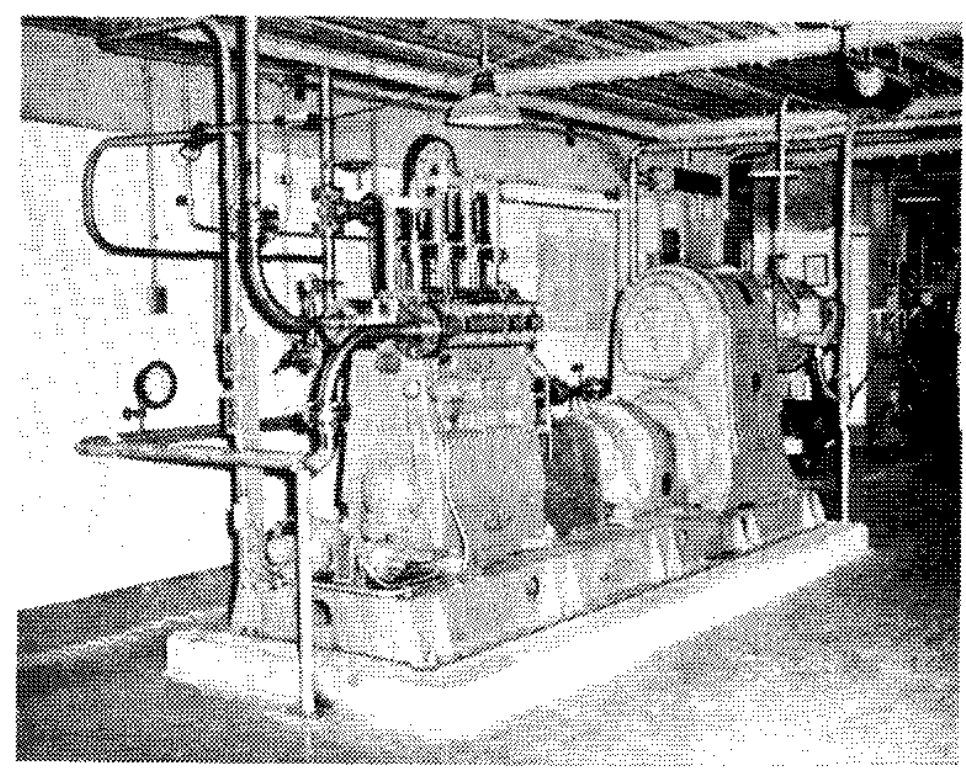

FUG. 5 HIGH PRESSURE PUMP FOR DECONTAMINATING EOUTPMENT 
flexible hose. In addition to the high-pressure system, both a conventional steam hydrocleaner and an injector-based hydraulic jet cleaner ("Super Booster Jet"*) are provided on the extension of the catwalk along one side of the cell, adjacent to the shielded operating area; these units are also connected to appropriate discharge nozzles in the tank by high-pressure flexible hose.

The nozzles, cleaning lances, and other devices can be picked up and directed by an electrically powered manipulator arm that is mounted on a vertical track and hoist in a corner of the tank near the shielding wall. The arm has an 8-ft reach, a vertical travel of $12 \mathrm{ft}$, and a lifting capacity of $150 \mathrm{lb}$ when fully extended (Figure 6). The controls for the high-pressure system and a simple portable console to direct the manipulator are located behind the shielding wall. In addition to directing the jets, the manipulator makes radiation surveys with instruments, makes smear surveys for contamination, positions mirrors for inspecting equipment, and performs other auxiliary tasks that were formerly done manually or could not be done if the radiation was prohibitive. The manipulator can also direct a small television camera for close inspection of equipment. Within the cell, the manipulator is supplemented by a $1 / 2$-ton $j i b$ crane. Heavy equipment is introduced and removed from the decontamination facility by a large bridge s crane that serves all of the shielded production line.

After remote decontamination, equipment for interim storage or disposal is transferred to the burial ground. Equipment that requires only minor maintenance is repaired remotely with the manipulator and returned to service with little delay. Some manual repairs are made when radiation levels permit personnel entry to the cell. Equipment that requires extensive repairs or modification is transferred to a section of the building more suitable for work with low to intermediate levels of contamination.

The high-velocity jet is used to remove nearly all of the smearable activity from the surfaces of process equipment. Major decontamination has been performed remotely with jets of hot water discharged at approximately $200 \mathrm{ft} / \mathrm{sec}$ from the hydraulic jet cleaner and with cold water discharged at about $650 \mathrm{ft} / \mathrm{sec}$ from the high-pressure pumping system. The jet techniques with water alone have two advantages: they are effective aids in the decontamination of equipment, and they do not contribute chemical reagents and detergents that must be retained in waste storage.

* Registered tradename of the Sellers Injector Corporation, Philadelphia, Pa. 


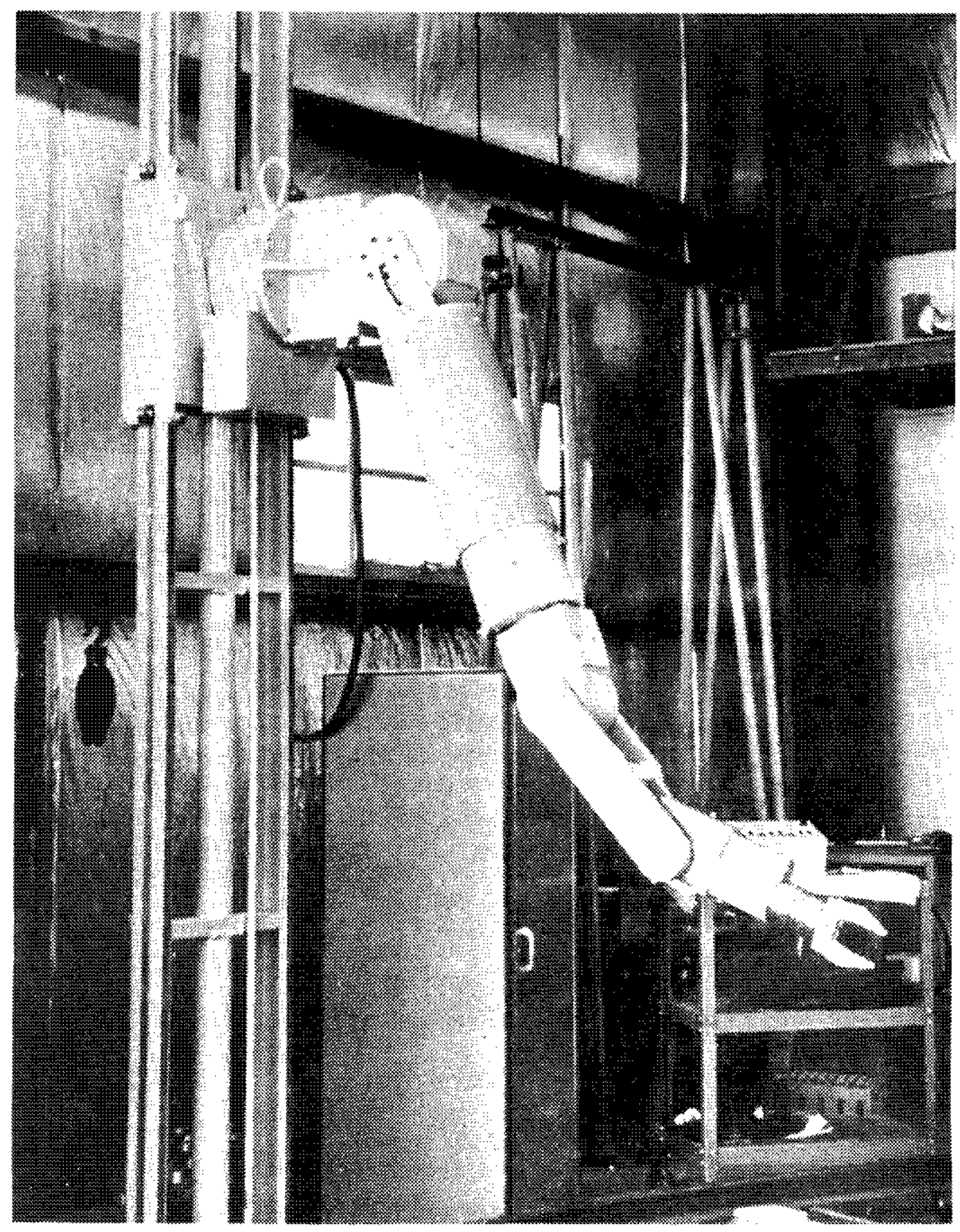

FIG. 6 ELECTROMECHANICAL MANIPULATOR 
The hydraulic jet cleaner has been used more than either the high-pressure system or the steam hydrocleaner. The unit is a modified injector which uses dry plant steam and cold water to develop pressures 2-4 times the pressure of the input steam; the stream of hot water is discharged at velocities of $120-250 \mathrm{ft} / \mathrm{sec}$ at $80-99^{\circ} \mathrm{C}$. Although detergents and other cleaning agents can be discharged through the hydraulic jet cleaner, water is generally used without additives. The major advantage of this equipment over the conventional steam hydrocleaner is the greater impact and cleaning range of the water jet relative to saturated steam and entrained clcaning agent; the hydraulic jet cleaner is most effective at 6-12 inches (Figure 7), but is still fairly effective even at $6 \mathrm{ft}$.

The steam hydrocleaner does not effectively decontaminate surfaces more than a few inches from the nozzle and is used principally to apply reagents or detergents where both heat and chemical action are needed, and where impact is less important. In normal practice, a combination of jet and chemical techniques may be used to obtain the desired degree of decontamination with minimum effort.

\title{
ACCOMPL ISHMENTS
}

Several hundred separate pieces of apparatus were decontaminated during the five years that the experimental facility was in use. They ranged from auxiliary parts of processing equipment (such as coverplates or thermowells that needed partial decontamination to permit rapid contact maintenance, perhaps the replacement of a gasket) to major units of equipment (such as centrifuges, which require extensive removal of radioactive contaminants to permit disassembly and overhaul). The facility became a functional adjunct to operations and a convenient means for reducing the problems associated with the maintenance of contaminated equipment. The decontamination facility also was included as a factor in long-range planning and scheduling of both manpower and process equipment. Some typical examples of equipment decontaminated for repair, reuse, or examination are:

\author{
9 Batch Evaporator Pots \\ 6 Agitators \\ 2 Batch Evaporator Condensers \\ 2 Continuous Evaporator Condensers \\ 6 Centrifuges \\ 2 Scrubber Pumps \\ 2 Resin Columns \\ 1 Dissolver Pot \\ 1 Fuel Storage Rack \\ 2 Transfer Pumps \\ 1 Barrier Wall Section \\ ح300 Miscellaneous I tems
}




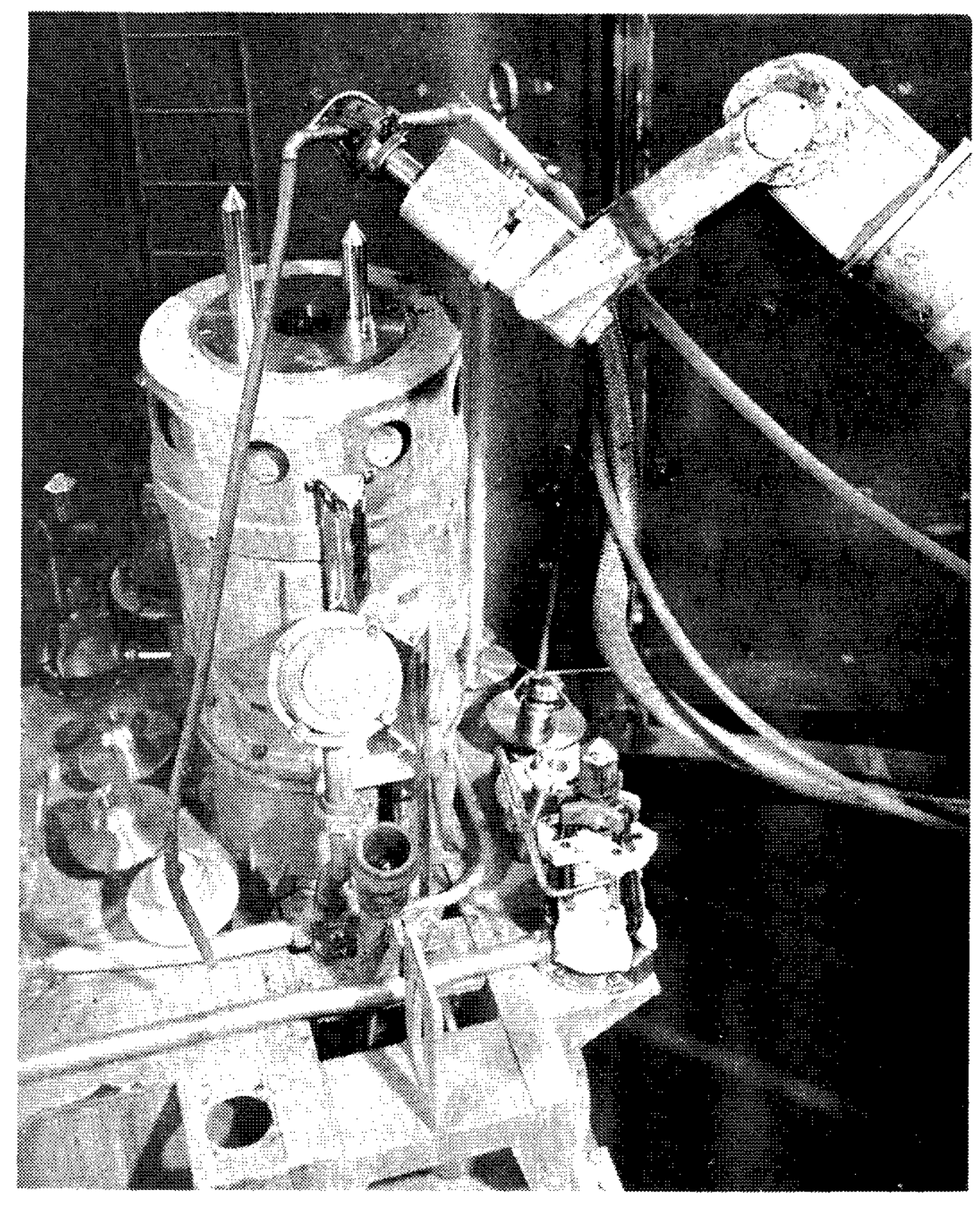

FIG. 7 DECONTAMNATING THE TOP OF A CENTRIFUGE 
The resulting savings on this equipment is shown in Table $I$.

The annual savings in equipment decontaminated is somewhat over $\$ 500,000$ for each of the separations plants.

TABLE I

TYPICAL SAVINGS ON EQUIPMENT

\begin{tabular}{lrrrrr}
\multicolumn{1}{c}{ Equipment } & \multicolumn{4}{c}{ Cost, $\$$} & \\
\cline { 1 - 1 } Centrifuge & 80,000 & 1,300 & 6,100 & 72,600 \\
Scrubber Pump & 16,000 & 500 & 1,500 & 14,000 \\
Agitator & 12,000 & 500 & 4,000 & 7,500 \\
Evaporator Pot & 65,000 & 11,000 & 31,000 & 23,000 \\
Evaporator Pot & 65,000 & 6,000 & 11,000 & 48,000 \\
Evaporator Pot & 65,000 & 3,000 & 31,000 & 31,000 \\
Centrifuge & 80,000 & 1,500 & 11,000 & 67,500 \\
Centrifuge & 80,000 & 1,000 & 11,000 & 68,000 \\
Evaporator Columns & $13)$ & 120,000 & 3,000 & 30,000 & 87,000 \\
Scrubber Pumps (2) & 16,000 & 1,000 & 2,000 & 13,000 \\
Evaporator Pot & 65,000 & 3,000 & 31,000 & 31,000 \\
Agitator & 12,000 & 1,000 & 1,000 & 10,000 \\
Agitators (3) & 30,000 & 1,500 & 3,000 & 25,500
\end{tabular}

As a result of the experience and accomplishments in the experimental decontamination facility, the heavy-duty electromechanical manipulator has been replaced with a new and improved model, and a remotely operated $j i b$ crane has been installed for increased efficiency and maneuverability. Some additional improvements are:

- A lift table for tools and attachments was placed in the cell below the shielding windows where it can be reached with the manipulator.

- A circulating pump for decontaminating solutions was installed to improve flushing of large equipment.

- The illumination was increased.

- Washers were provided for the in-cell sides of the windows in the shielding wall.

In addition to the improvements made in the original facility, a similar decontamination facility was installed in the companion separations plant. 
The types of work now done routinely include many not contemplated when the first facility was completed. For example, a dissolver that had been in use for several years (in good working order but not needed for current production) was cleaned enough to permit above-ground storage. Formerly, such a vessel would either be stored behind shielding in the process building or be buried. Another example has been the cleaning of crane hooks used to charge dissolvers. These hooks are often sources for spreading contamination to other sections in the process area. Manual contact decontamination, formerly standard practice, resulted in undesirable exposure to personne1. Now the hooks are cleaned routinely in the decontanination facilities with little exposure, lower cost, and little spread of contamination.

The shielding wall with windows and access ports, the manipulators, and the high-velocity jets were also beneficial in that a number of support operations have been performed in addition to decontaminating equipment in each of the plants. The fact that the decontamination facilities are within the separations process buildings has been a major factor in this use. For example, if a connection on a remotely attached pipe jumper does not "make up" as it should, or an instrument reports unexplainable information, the quickest way to diagnose such problems is by direct observation. Previously, hours or even days of trials and deductions were needed to determine the trouble; now a moment of observation may provide the answer. occasionally a minor adjustment can be made with the manipulator or manually through the access ports in the shielding wall. Flanges, gaskets in connectors, and damaged equipment have also been inspected.

The high velocity jets have been used to remove old gaskets from connectors and to scour residual gasket material from flanges of 1 arge condensers and other equipment, so that personnel were not required to enter high radiation fields. A number of these operations as well as other routine tasks, such as making radiographs of contaminated equipment and measuring connectors before remote installation on process vesse1s, have been performed with the manipulators. 


\section{ACKNOWLEDGMENTS}

The author wishes to acknowledge the assistance of the Dowell and Dow Industrial Service divisions of the Dow Chemical Company on the technology of highpressure jetting. 


\section{APPENDIX}

\section{ABRASIVE CLEANING}

Abrasive cleaning is the impingement of a stream of abrasive material at high velocity against a surface. The abrasive may be propelled by water at high pressure, by centrifugal force, or by compressed air. The action can be varied to polish, scour, or peen the surface, depending upon the type of abrasive and the conditions of application.

Where applicable, abrasive cleaning is a rapid, effective, and economical means for removing contaminated paint and for removing some of the surface of concrete and metal objects. Abrasive cleaning has been used where other methods have been inadequate or too slow. The applications have been limited primarily to the walls and floors of buildings and to the exterior surfaces of process equipment, vehicles, heavy equipment, and other surfaces where rather severe roughening of the surface does not destroy the usefulness of the item that is decontaminated. Surface removal by abrasive blasting is most commonly used on porous surfaces, such as concrete, where activity has penetrated to the extent that it is not effectively removed by liquid cleaning methods.

Abrasive cleaning includes both wet and dry methods, with many variations in techniques and equipment and a broad selection of abrasive materials. As in chemical decontamination, there is no single technique or abrasive material that is universally applicable. The material of construction of the contaminated surface or equipment, the area and complexity of the surface, the level and type of contamination, and the extent to which the surface must be decontaminated must be considered.

Some disadvantages inherent in decontamination limit the effectiveness and the applications of abrasive cleaning. For example, minute amounts of dirt, grease or other solids retained in small holes, fillets, cracks, and crevices found on most equipment is not a serious problem in ordinary industrial cleaning. However, with contaminated equipment, such residues contain radioactive material and therefore must be removed. If the confined areas are smaller than the abrasive, the soil is not removed unless enough surface is removed to eliminate the confined area, and such drastic treatment can severely damage the equipment. Finished surfaces, as well as edges and corners that need to retain their sharpness, are likely to be damaged unless cleaned with soft 
abrasives, fine abrasives applied at reduced velocity, or fine abrasives applied by wet methods. Such mild treatments may not provide adequate decontamination.

\section{DRY BLASTING}

Dry blast cleaning with ordinary sand propelled by compressed air is one of the most widely used techniques because it is simple and versatile. Normal commercial sand averages about 50 mesh (range 20-100) and is a compromise between the rapid action of coarse abrasive and minimum surface damage obtained with fine abrasive. Fine sand of about 100 mesh causes correspondingly less damage, but the cleaning action is very slow, and the dust is difficult to retain, making it necessary to use containment or other means of dust control.

Even with fine sand or mineral abrasives, the cutting action in dry abrasive blasting is not easy to control. The amount of surface removed and the rate of removal depend on the skill and attention of the operator as well as the physical characteristics of the abrasive and the air pressure.

Although dry sandblasting is very effective for decontamination, extreme care is required to control the airborne dust. The dust is very difficult to remove from other surfaces, especially from protective clothing. ${ }^{37}$ The dust can be controlled by enclosing the cleaning operation, maintaining the enclosure under negative pressure, and filtering the airborne dust from the exhaust air. If the abrasive is to be reused, the good abrasive must be separated from the fines in a separate system because the exhaust removes only the material that is airborne. The abrasive is usually allowed to fall into a bin or collection chamber under the enclosure so that it can be removed for disposal or for screening and recovery. The enclosure and the air control reduce the economic advantage of dry blast cleaning and place physical restrictions on the size and ease of handing of the equipment that is to be decontaminated.

Metal oxide abrasives are less friable than sand and are suitable for reuse. Stainless steel laboratory equipment has been decontaminated ${ }^{34}$ at Hanford in a small ventilated cabinet by carborundum mixed with $10 \%$ aluminum oxide and propelled by air at about 25 psig. An estimated $99 \%$ of the activity was removed. Over a perind of several months, some beta-gamma activity was, retained on the abrasive, but no alpha activity was detected. No problem was encountered with dust or airborne activity outside the containment cabinet. 
Very little dust is produced by metallic abrasives, and if they can be reused without a contamination or radiation problem, the life is 20 to 100 times that of sand, depending on the material. Steel abrasive has a much longer life than iron. Cut steel wire and steel and iron shot have been investigated to a limited extent ${ }^{57}$ for the removal of moderate levels of activity from contaminated steel equipment where precision and finished surfaces were not involved, and for partial decontamination of nonrecoverable items before disposal. The retention of activity on the metallic abrasives was not a problem in the low level work, but further investigation is necessary to establish limitations for applications with highly contaminated equipment.

\section{WET BLASTING}

Wet blasting techniques are better than dry blasting techniques for maintaining fine finishes, and they also provide substantial scouring action for effective decontamination. By selection of method and choice of abrasive, the cleaning action can be varied from fine scouring to rapid, coarse cutting. With appropriate fine abrasives, it is possible to maintain a finish with less than one mil loss.

In wet sandblasting, common sand is mixed with water, and the mixture is propelled by compressed air. Commercial equipment is available to provide appropriate mixtures. Blasting with wet sand is fast and is often used commercially to clean large surfaces when dust must be avoided.

Two disadvantages are inherent in the application of wet blasting to decontamination: 1) the waste water as well as sand must be retained and monitored before disposal, and 2) fine sand particles that are formed by comminution of the abrasive are wet, adhere strongly to the metal surfaces that have been cleaned, and have to be removed by brushing. The water may also wash the fine abrasives into cracks, holes, and other confined areas so that additional effort is required to remove the residual abrasive material even after it is dried.

At the Savannah River Plant, wet blasting has been very effective in avoiding airborne contamination during decontamination of equipment that would otherwise be cleaned by dry sandblasting. In a typical application, wet sand was used to decontaminate a cask for transporting irradiated fuel. The beta-gamma radiation was reduced by a factor of 100 without difficulty. The wet blast from a conventional straight nozzle was very effective on flat surfaces, but was less effective on less accessible areas such as the inside cavity and areas between the cooling fins of the cask. Nozzles with a $45^{\circ}$ 
offset were used to decontaminate these areas. Wet sandblasting did not remove contamination from blind holes for threaded bolts. Other items decontaminated by wet sandblasting include tanks and heating and cooling coils from contaminated vessels. Difficulty was encountered in removing all of the fine comminuted sand from flat surfaces as well as from corners and crevices. Development work on the use of wet honing to decontaminate finished surfaces such as flanges was discontinued after the application of dilute chemical reagents with jets, and the successful demonstration of high-velocity jets of water for general decontamination. 


\section{BIBLIOGRAPHY}

1. E. H. Armbruster and G. M. Ridenaur. "Detergency Measurement." Soop and Sanitary Chem. 28(6), 83 (1952).

2. P. J. Barry. "Some General Considerations in Chemical Decontamination." Health Physics 1, 184 (1958).

3. L. M. Behr and W. L. Bryant. "Radioactivity Decontamination by Ultrasonics." Proceedings of the 7th Hot Laboratories and Equipment Conference. American Society of Mechanical Engineers, New York (1959).

4. M. R. Bennett. Electrodecontamination of Stainless Steel. AECD-4169, Oak Ridge National Laboratory, Oak Ridge, Tenn. (1955).

5. M. R. Bennett. Evaluation of Reagent Decontomination. USAEC Report ORNL-Cf-51-11-123, Oak Ridge National Laboratory, Oak Ridge, Tenn. (1951).

6. W. B. Blumenthal. The Chemical Behavior of Zirconium. Van Nostrand, Princeton, N. J. (1958).

7. W. E. Bost. Radioactive Decontamination. USAEC Report TID-3535, Technical Information Service, Oak Ridge, Tenn. (1959).

8. F. N. Browder. Sumary of Surface Decontamination Experience. AECD-3998, Oak Ridge National Laboratory, Oak Ridge, Tenn. (1956).

9. D. 0. Campbe11. Decontomination of the Homogeneous Reactor Experiment. USAEC Report ORNL-1839, Oak Ridge Nationa1 Laboratory, Oak Ridge, Tenn. (1956).

10. D. 0. Campbe11. Decontomination of Stainless Steel, Sumey and Proposed Program. USAEC Report ORNL-CF-53-5-233, Oak Ridge National Laboratory, Oak Ridge, Tenn. (1953).

11. D. 0. Campbe11. The Decontamination of Stainless Stee I. USAEC Report ORNL-CF-54-3-71, Oak Ridge National Laboratory, Oak Ridge, Tenn. (1954).

12. J. B. Campbel1. "Selecting Metal Cleaning Methods." Material and Methods 38(5), 119 (1953).

13. W. H. Carr. "Decontamination Hazards." Nuclear Safety 1(2), 39 (1959).

14. S. Chaberek and A. E. Martell. Organic Sequestering Agents. John Wiley, New York (1954).

15. E. L. Chrisiansen. Procedures for Decontamination of Plutonium from Various Surfaces. USAEC Report LAMS-2319, Los Alamos Scientific Laboratory, Los Alamos, New Mexico (1959). 
16. N. J. Clayton. Effects of Radiation and Contamination on a Polyester Resin Protective Coating. USAEC Report WAPD-CTA(EC)-305, Westinghouse Electric Corp., Atomic Power Division, Pittsburgh, Pa. (1957).

17. B. V. Coplan and D. J. Smith. "Remodeling a High-Level Chemistry Cel1." Nucleonics 12(11), 92 (1954).

18. R. L. Curtis. Decontamination - A Literary Search. USAEC Report Y-964, Carbide and Carbon Chemicals Co., Y-12 Plant, Oak Ridge, Tenn. (1953).

19. F. Fairbrother and J. B. Taylor. "Water-Soluble Complexes of Niobium (Columbium) and Tantalum. Part I. Complexes with $\alpha-$ Hydroxyacids and (2-Hydroxyethyl) Amines." J. Chem. Soc. 1956, 4946 (1956).

20. M. L. Feldman and R. F. Rogers. Development of Decontamination Peagent. USAEC Report ORNL-CF-53-1-283, Oak Ridge National Laboratory, Oak Ridge, Tenn. (1953).

21. M. G. Fontana. Corrosion - A Compization. The Press of Hollinbach, Columbus, Ohio (1957).

22. H. V. Garabedian. Decontamination and Corrosion Resistance of Selected Coatings. AECU-4187, Oak Ridge National Laboratory, Oak Ridge, Tenn. (1959).

23. B. W. Gonser and E. M. Sherwood. Technology of Columbium (Niobium). John Wiley, New York (1958).

24. B. Griggs. The Decontamination of Reactors and Reactor Loops A Literary Review. USAEC Report HW-57642, Hanford Atomic Products Operation, Richland, Wash. (1958).

25. W. W. Hawes. Survey of Decontamination Methods. ADC-48, U. S. Naval Radiological Defense Laboratory, San Francisco, Calif. (1948).

26. W. W. Hawes and L. Leventhal. Survey of Decontamination. III. Decontominability of Metals and Alloys. ADC-75, U. S. Naval Radiological Defense Laboratory, San Francisto, Calif. (1949).

27. R. H. Heiskell, et al. Effects of Elevated Temperatures on the Properties of Portzand Cement Mixtures, Related to Surface Removal and Decontamination. USNRDL-TR-60, U. S. Naval Radiological Defense Laboratory, San Francisco, Calif. (1955).

28. J. W. Hensley, et al. "A Metal Cleaning Test Using Radioactive Stearic Acid as Soi1." Papers on Evaluation of Soaps and Detergents. ASTM Special Technical Publication No. 115, Philadelphia, Pa. (1952).

29. J. W. Hensley, et a1. "Reactions of Ions in Aqueous Solution with Glass and Metal Surfaces." Ind. Eng. Chem. 41(7), 1415 (1949). 
30. "Hot" Laundry Cools Equipment." Chem. Eng. News 36, 117 (September 1, 1958).

31. "How Radiation Affects Materials." Nucleonics 14(9), 55-58 (1956).

32. J. B. Huff. "Electrodecontamination of Metals." Nucleonics $14(6), 70(1956)$.

33. J. B. Huff. "Tests of Decontaminants for Lead, Steel and Glass." Nucleonics 15(6), 106 (1957).

34. L. E. Kattner. Sandblast Decontomination of Stainless Steel. USAEC Report HW-29576, Hanford Atomic Products Operation, Richland, Wash. (1953).

35. P. S. Kingsley. Disposition of Contaminated Process Equipment, 1958-1959. USAEC Report HW-63703, Hanford Atomic Products Operation, Richland, Wash. (1960).

36. P. S. Kingsley and M. L. Short. Decontamination. USAEC Report HW-63110, Hanford Atomic Products Operation, Richland, Wash. (1960).

37. P. B. Klevin, et a1. Decontamination of Buildings Used for Processing Alpha Emitters. USAEC Report NYO-4600, New York Operations Office, National Bureau of Standards, Washington, D. C. (1954).

38. T. V. Lane. Corrosion Effects of a Tureo 4306-B Simulated Flush on a 1706-KE Mock-up Tube. USAEC Report HW-55854, Hanford Atomic Products Operation, Richland, Wash. (1958).

39. R. Lloyd. Decontaminability of Structure Materials and Surface Coatings for Use in Nuclear InstaZlations. USAEC Report WAPDPWR-CP-3052, Westinghouse Electric Corp., Atomic Power Division, Pittsburgh, Pa. (1957).

40. C. P. McCord and R. L. Robertson. "The Appraisal of Detergency through Radioactive Isotopes." Industrial Medecine and Surgery 19. 554 (1950).

41. K. H. McCorkle and W. R. Winbro. Decontcomination of the ORNL Thorex Pilot Plant. USAEC Report ORNL-2058, Oak Ridge National Laboratory, Oak Ridge, Tenn. (1956).

42. H. A. McLain. Decontomination of the PFER Pizot Leaching Plant. USAEC Report ORNL-CF-59-7-75, Oak Ridge National Laboratory, Oak Ridge, Tenn. (1959).

43. J. A. McLaren, J. H. Goode, and H. L. Peeler. EZectrochemical Studies: Quarterly Report for Period November 10, 1951 February 10, 1951. USAEC Report ORNL-CF-52-2-217, Oak Ridge National Laboratory, Oak Ridge, Tenn. (1955).

44. C. F. Miller. Theory of Decontamination, Part I. USNRDL-460, U. S. Naval Radiological Defense Laboratory, San Francisco, Calif. (1958). 
45. G. A. Nelson. Corrosion Data Survey. Shell Development Co., San Francisco, Calif. (1950).

46. W. A. 01dham. Summary of Decontomination Studies in the 1706-KER for the Period January 1, 1958 to October 1, 1958. USAEC Report HW-57635, Hanford Atomic Products Operation, Richland, Wash. (1958).

47. 0. L. 01son and J. F. Gifford. Facilities for Decontamination of Laboratory Equipment. USAEC Report HW-26502, Hanford Atomic Products Operation, Richland, Wash. (1953).

48. J. R. Parrott. Evaluation of the Turco 4501 Process for the Decontamination of the Thorex Dissolver. USAEC Report ORNL-CF59-1-23, Oak Ridge National Laboratory, Oak Ridge, Tenn. (1959).

49. L. D. Perrigo, Jr. Interim Report No. 1 on the Turco 4501 Process for the Decontamination of Stainless Steel. USAEC Report HW-56090, Hanford Atomic Products Operation, Richland, Wash. (1958).

50. Proposed Procedures for Chemical Decontomination of PWR. USAEC Report WAPD-PWR-CP-2719, Westinghouse Electric Corp., Bettis Plant, Pittsburgh, Pa. (1957).

51. Radioactive Decontamination Procedures and Equipment. IGRLIB/R-27, United Kingdom Atomic Energy Authority, Resley, Lancs, England (1957).

52. Reactor Chemistry and Plant Materials. Bettis Technical Review. USAEC Report WAPD-BT-3, Westinghouse Electric Corp., Atomic Power Division, Bettis Plant, Pittsburgh, Pa. (1957).

53. H. J. Reind1. "Coatings and Finishes." Mech. Eng. 79(8), 730 (1957).

54. R. L. Rod. "Recent Advances in U1trasonic Decontamination." Nucleonies 16(7), 104 (1958).

55. G. S. Sadowski. "Decontamination of Processing Plants." Nucleonics 15(3), 68 (1957).

56. A. E. Sa1o. Treating Concrete Surfaces with Paraffin. UCRL-2988, University of California, Berkeley Radiation Laboratory, Berkeley, Calif. (1955).

57. J. W. Savage and D. J. Stoker. Equipment Decontamination by Abrasive Blasting in the Processing Refabrication Experiment. NAA-SR-3261, Atomic Internationa1, North American Aviation, Inc., Canooga Park, Calif. (1959).

58. G. Schwarzenbach. "Relationship Between Metal Complex Stability and the Structure of Complexing Agents." Anal. Chem. 32(1), $6(1960)$. 
59. G. Segura. "Detergency as Applied to Radiological Decontamination." Chem. Ind. 1953, 1270 (1953).

60. R. K. Skow, et al. "Hazard Evaluation and Control After a Spill of $40 \mathrm{mg}$ of Radium." Nucleonics 11(8), 45 (1953).

61. L. F. Spencer. "Proper Cleaning Methods, Pay Dividends." Metal Finishing 55(4), 56 (1957).

62. C. E. Stevenson. Technical Progress Report, Apriz - June 1958. USAEC Report IDO-14453, Phil1ips Petroleum Company, Atomic Energy Division, Idaho Fal1s, Idaho (1958).

63. C. E. Stevenson. Technical Progress Report, January - March 1959. USAEC Report ID0-14471, Phillips Petroleum Co., Idaho (1959).

64. W. H. Sullivan. Chapter 10 - Decontamination; Radiological Defense, Vol. II. AD-206(Y), U. S. Naval Radiological Defense Laboratory, San Francisco, Calif. (1950).

65. A. P. Talboys. Contamination of Metal Surfaces by $I^{131}$ in Solution. USAEC Report NYO-1573, New York Operations Office, Johns Hopkins University, Baltimore, Md. (1951).

66. P. C. Thompkins, et al. "Working Surfaces for Radiochemical Laboratories - Paints, Plastics, and Floor Materials." Ind. Eng. Chem. 42(8), 1475 (1950).

67. P. C. Tompkins and O. M. Bizze11. 'Working Surfaces for Radiochemical Laboratories - Glass, Stainless Steel, and Lead." Ind. Eng. Chem. 42(8), 1469 (1950).

68. C. M. Unruh. Chemical Decontomination of the Internal Surfaces of Reactor Coolant Septems. USAEC Report HW-54509, Hanford Atomic Products Operation, Richland, Wash. (1958).

69. E. M. Vander Wall and E. M. Whitener. "Concentrated Nitric and Dilute Hydrofluoric Acid Mixtures in the Dissolution of Zirconium Meta1." Ind. Eng. Chem. 51(1), 51 (1959).

70. C. D. Watson. A General Decontamination Manual for the Idaho Chemical Processing Plant. USAEC Report IDO-26081, Oak Ridge National Laboratory, Oak Ridge, Tenn. (1953).

71. C. D. Watson, et al. Decontamination and Corrosion Resistance Properties of Selected Laboratory Surfaces. AECD-2996, Oak Ridge National Laboratory, Oak Ridge, Tenn. (1950).

72. G. A. West and C. D. Watson. Decontomination Testing of Highly Contaminated Protective Coatings. USAEC Report ORNL-2811, Oak Ridge National Laboratory, Oak Ridge, Tenn. (1960). 